It should be emphasized that a massive diuresis is not an obligatory stage in recovery, that when it occurs it is due to previous overhydration and should not therefore be treated by fluid replacement. The emphasis is necessary because numerous recent publications still advise this treatment, which can only perpetuate the overhydration and cause electrolyte loss.

The determining factor in deciding the nature of a diuresis is the urine osmolality. If this is hypotonic it is one of water and an increasing intake is not desirable. If it is isotonic or hypertonic it is one of solutes and an increased fluid intake may be encouraged. In practice it is generally safe at this stage to allow a free intake; but some patients then, as a reaction to prolonged deprivation, drink excessively (although one patient was afraid to drink at all in case she still could not pass it).

In this work there is no consistent difference between the urines of cases with chronic failure or acute failure which could help in deciding between the two conditions. The absence of any difference has already been emphasized by Franklin and Merrill (1960), but clinicians continue to seek for one. Prerenal conditions, such as a marked reduction in food and water intake, may also produce oliguria and a relatively dilute urine. Joekes et al. (1957) consider that such urines can be distinguished by their low sodium concentration; but this is uncertain, since similar low concentrations are seen here in acute failure.

\section{Summary}

The concentration of urea, electrolytes, and total osmols was studied in the urines of patients with acute and chronic renal failure. No differences which could be used in distinguishing the two conditions were found.

Patients with chronic failure, when neither dehydrated nor overhydrated, passed urine which was hypotonic to or isotonic with plasma and never hypertonic. Those with acute failure also often passed hypotonic urine at first, the osmolality increasing to that of plasma or slightly more with improvement. This, since the fluid intake was strictly limited, shows an inability to concentrate, which resulted in an increase in urine volume as solute excretion increased. Improvement in concentrating power was slow, but recovery, as shown by excretion of retained urea, occurred satisfactorily with these dilute urines, although the daily urine volumes were often only about 1.5 litres and did not exceed 3.5 litres. High volumes suggest previous or concurrent overhydration, which can be confirmed by the finding of hypotonic urine. The fluid intake under these circumstances should be less than the output.

My thanks are due to Professor D. A. K. Black, whose patients were investigated.

\section{REFERENCES}

Baker, S. B. de C., and Williams, R. T. (1963). Brit. med. 7., 1, 1655. Baldwin D. Se Berman H. J Heinemann, H. O., and Smith, H. W. (1955). \%. clin. Invest., 34, 800.

Bull, G. M. (1956). In Modern Views on Secretion of Urine, edited by F. R. Winton, p. 256. Churchill, London.

Franklin, S. S., and Merrill, J. P. (1960). New Engl. F. Med., 262, 711, 761.

Iseri, L. T., Batchelor, T. M., Boyle, A. J., and Myers, G. B. (1952). Arch. intern. Med., 89, 188.

Joekes, A. M., Mowbray, J. F., and Dormandy, K. (1957). Lancet, 2, 864.

Kleeman, C. R., Adams, D. A., and Maxwell, M. H. (1961). 7. Lab. clin. Med., 58, 169 .

Roscoe, M. H. (1960). F. clin. Path., 13, 514.

Swann, R. C., and Merrill, J. P. (1953). Medicine (Baltimore), 32, 215.

\title{
Multiple Attacks of Aseptic Meningitis in the Same Individual
}

\author{
ERKKI KLEMOLA,* M.D.; KAISA LAPINLEIMU,* M.D.
}

Brit. med. F., 1964, 1, 1087-1090

Interest has recently been focused on patients suffering from multiple attacks of suppurative meningitis. In most of these cases it is possible to establish as the predisposing factor an earlier trauma which has left anatomical changes in the base of the skull that make it easier for bacteria to invade the central nervous system.

How common is it, then, for a person to have several attacks of aseptic meningitis or acute infectious encephalitis? So far as we have been able to establish, no reference has been made to the subject in the literature. Only recently have advances in virology made it possible to establish the viral aetiology and make a specific diagnosis in a considerable proportion of aseptic meningitides and encephalitides. Moreover, even in the cases in which virological studies do not yield a positive result, there are nowadays better chances of excluding with high probability other aetiological factors causing diseases of the central nervous system.

\section{Own Patients. Criteria for Aseptic Meningitis}

We have personally had an opportunity of examining and following four patients who have had the syndrome of aseptic meningitis two to four times-in all 11 times-during observation periods of $1 \frac{1}{2}$ to 11 years.
The signs and symptoms in all attacks fulfilled Arvid Wallgren's (1925) criteria for the diagnosis of aseptic meningitis: (1) acute onset with obvious signs and symptoms of meningeal involvement, (2) alteration of cerebrospinal fluid typical of meningitis, (3) absence of bacteria in cerebrospinal fluid, as demonstrated by appropriate direct or cultural techniques, (4) relatively short benign course of illness, (5) absence of local parameningeal infection (otitis, sinusitis, trauma, etc.), or a general disease which might present meningitis as a secondary manifestation.

Later authors have accepted Wallgren's criteria, but many have preferred other names-for example, viral meningitis and primary serous meningitis-for this syndrome. Since these terms also have their shortcomings aseptic meningitis is still used at least as a synonym. In addition to many viruses some other micro-organisms, especially leptospires, may cause the syndrome. However desirable an aetiological diagnosis in each individual case, for practical purpose the syndrome must have a designation, as the aetiology is often established only when the disease has already been cured, and often remains obscure. When, in addition to meningeal symptoms, there is anything suggestive of deeper involvement of the central nervous system

\footnotetext{
^ From Aurora Hospital and from the State Serum Institute, Helsinki, Finland.
} 
(C.N.S.) there is reason to speak in the clinical sense of meningoencephalitis and not of aseptic meningitis. But, of course, there is no sharp distinction between these clinical conditions. Each aetiological agent is able to produce diverse clinical manifestations of disease.

Table I shows the age of the patients at the time of the first attack of the disease, their sex, and the month and year of the attacks. Two of the patients were adults and two children; three were males. One patient had aseptic meningitis four times, one had it three times, and two had it twice. The interval between attacks was four months to eight years; it was under two years in only two cases. The disease began in the period August-October six times, in the winter and spring seasons five times. For both attacks in Case 4 and for the second attack in Case 3, the patients were admitted to the Children's Hospital, University of Helsinki, otherwise the patients were treated at Aurora Hospital.

TABLE I.-Some Data on the Four Cases of Aseptic Meningitis

\begin{tabular}{|c|c|c|c|c|c|c|}
\hline \multirow{2}{*}{$\begin{array}{l}\text { Case } \\
\text { No. }\end{array}$} & \multirow{2}{*}{$\begin{array}{l}\text { Age at } \\
\text { First } \\
\text { Attack }\end{array}$} & \multirow{2}{*}{ Sex } & \multicolumn{4}{|c|}{ Month and Year of Attack } \\
\hline & & & First & Second & Third & Fourth \\
\hline $\begin{array}{l}1 \\
2 \\
3 \\
4\end{array}$ & $\begin{array}{r}21 \\
31 \\
4 \\
12\end{array}$ & $\begin{array}{l}\mathbf{M} \\
\mathbf{M} \\
\mathbf{M} \\
\mathbf{F}\end{array}$ & $\begin{array}{r}\text { III/1952 } \\
\text { III/1952 } \\
\text { VIII } / 1954 \\
\text { IX } / 1961\end{array}$ & $\begin{array}{r}X / 1958 \\
V / 1957 \\
X / 1962 \\
I / 1962\end{array}$ & $\begin{array}{r}\text { V/1961 } \\
\text { VIII/1961 }\end{array}$ & $X / 1962$ \\
\hline
\end{tabular}

\section{Clinical and Laboratory Findings}

In the history of the patients there was nothing indicative of earlier cranial trauma or suppurative meningitis. The patients had not been unusually prone to acute respiratory infections or other infectious diseases. The onset of the illness was sudden, the patient having previously been completely healthy. There was fever $\left(38.2-39.8^{\circ} \mathrm{C}\right.$.), headache, and nausea or vomiting in all the cases, but the general condition was nevertheless good. The duration of the fever was from 2 to 10 days (Table II). Stiffness of the neck and back was present in all the cases. There were no symptoms or signs indicative of deeper involvement of the central nervous system to justify a diagnosis of encephalitis. Otological, rhinological, and ophthalmological findings were normal. There was nothing indicative of a respiratory disease.

Table II shows that the erythrocyte sedimentation rate (E.S.R.) and the leucocyte count were normal or slightly elevated. Paper-electrophoresis and immuno-electrophoresis patterns were normal in the serum of all the patients. $X$-ray films of the skull were normal. Electroencephalograms (E.E.G.) were taken two to three times for all patients. The finding was within normal limits except in Case 2, where the E.E.G. was definitely pathological during the third attack, but a year later the abnormal changes had almost disappeared.

The results of the cerebrospinal fluid (C.S.F.) examinations can be seen from Table II. The highest spinal fluid cell counts ranged from 38 to $1,707 / \mathrm{c} . \mathrm{mm}$. The majority of the cells were lymphocytes except in two attacks, when 69 and $81 \%$ of the cells were polymorphonuclears at the first lumbar puncture. The total protein was elevated $(50-146 \mathrm{mg} . / 100 \mathrm{ml}$.) except in two attacks. Glucose and chloride values were normal. The C.S.F. pressure was within the normal range in the two patients (Cases 1 and 2) in whom it was measured. Pleocytosis disappeared completely or almost completely within two to six weeks in six attacks. The C.S.F. cell count at the last examination was 3 to 19 . In five attacks the last lumbar puncture was made one to three weeks from the onset of the disease and the cell count was then still 27 to 96 . One of the patients had been hospitalized for another disease in the interval between the second and third attacks of meningitis and the C.S.F. was completely normal.

The patients, who had been healthy prior to the meningitis, recovered within two months at the latest. A follow-up examination was made on all of them at the end of 1962 or beginning of 1963, when 2 to 18 months had elapsed from the last attack. Nothing abnormal was found.

\section{Microbiological Studies}

Material and Methods.-Stool and blood specimens were collected from the patients during the first 48 hours after admission. A second blood sample was drawn 10 to 14 days later, and in certain cases a third was taken about a week after the second. Sera were separated as soon as possible in the laboratory, inactivated at $56^{\circ} \mathrm{C}$. for 30 minutes, and stored at $4^{\circ} \mathrm{C}$. Stool samples were stored at $-20^{\circ} \mathrm{C}$.

Virus Isolations and Identifications.-Before the year 1955 no attempt was made to isolate viruses from stools. During 1955-9 all examinations for the presence of enteroviruses in stools were performed with the aid of tissue cultures of human fibroblasts or primary human amnion cells. But after 1959 all samples were routinely inoculated into each of two respective tissue cultures: primary human amnion cells, U-cells (a cell line of human amnion cells), and monkey-kidney cells. The cell cultures were examined twice weekly for 10 to 20 days, depending on the type of culture, the medium being changed when necessary. The specimens considered negative in tissue cultures were also inoculated into newborn mice (Case 1 in 1961 and Case 2 in 1961). All the viruses isolated were identified by the neutralization test with rabbit hyperimmune serum produced in our laboratory.

Serological Tests.-Standard serological tests for syphilis and leptospiral agglutinins were carried out in all cases. Since 1957, haemagglutination-inhibition tests for louping ill have been carried out in every case. Up to 1957 , complement-fixing (C.F.) antibodies were determined only against parotitis and polio $1-3$, but since that year C.F. antibody determinations against ornithosis, adenoviruses, and herpes simplex viruses have also been performed. In most cases tests for C.F. antibodies were made by a micromethod employing 2 units of complement. In the neutralization tests $100_{50}$ TCD of virus and in the majority of cases a series of fourfold dilutions of the serum, beginning with $1: 4$, were used. The mixtures of virus and serum were allowed to react at room temperature for two hours before inoculation into tissue cultures. The highest dilution of serum inhibiting the cytopathic effect of the virus (CPE) was taken as the titre of the neutralizing antibodies. On the

TABLE II.-Some Clinical and Laboratory Data

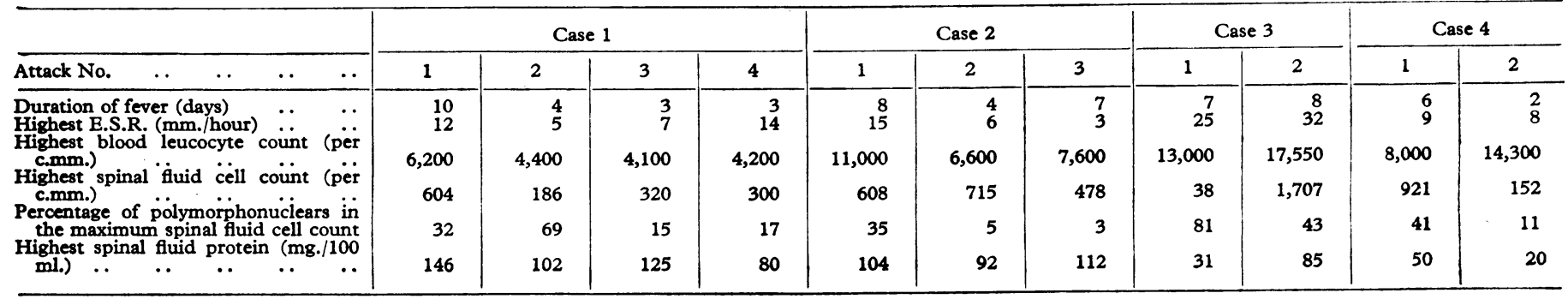


last occasion when Cases 1 and 2 were admitted to hospital the neutralizing antibody determinations for viruses known to have been prevalent in Finland in the past few years were carried out. The determinations were made simultaneously from all refrigerated sera of these patients. The enteroviruses that have been common in the past few years in Helsinki are E.C.H.O. 9 in 1958, Polio 1 and E.C.H.O. 7 in 1960, Coxsackie B5 in 1961-2 on several occasions, and Coxsackie B2 a few times. During 1960-1 many strains of E.C.H.O. 11 were also recovered from sewage.

\section{Results of Microbiological Studies}

The virus isolations and the antibody responses to the probable aetiological agents are presented in Table III.

In Case 1 the aetiology of the diseases in 1952 and 1958 could not be established. The attack in 1961 seems to have been associated with E.C.H.O. 7 virus. An attempt to isolate the virus from the patient's stools was unsuccessful, but the patient responded with a rise in antibodies only against E.C.H.O. 7 virus from $1:<4$ to $1: 64$ during his illness. In 1962 the aetiological significance of Coxsackie B5 isolated from the patient's stools was supported by the homotypic antibody response from $1:<4$ to $1: 64$. Thus in this case it seems that the two later attacks of meningitis were of different aetiology.

In Case 2, during the second attack in 1957, a transmissible agent from the stools was isolated in human fibroblasts. It was not any of the three polio types, but at that time further identification was not possible. During the third attack no virus from the stools could be isolated. There was still some serum left from the acute phase in 1957, but unfortunately not from the convalescent phase. In the neutralizing antibody determinations the antibodies against E.C.H.O. 9 alone showed a rise from $1: 4$ in 1957 to $1: 16$ in 1961. Although E.C.H.O. 9 was prevalent in Finland in 1957-8 and the CPE in the tissue culture from the stools of this patient in 1957 may have been caused by E.C.H.O. 9, we cannot confirm it for lack of convalescent serum from 1957. Thus the aetiological agent or agents could not be identified with certainty in any of the attacks suffered by this patient, although for 1957 E.C.H.O. 9 is suspected.

In Case 3 Coxsackie B5 was isolated from the stools in 1962 and the homotypic antibody titre showed a rise from $1:<4$ to $1: 64$, suggesting that the second attack was associated with Coxsackie B5.

In Case 4, one of the first Coxsackie B5 isolations of the 1961-2 epidemic was obtained from stools of this patient. Neutralizing antibodies against Coxsackie B5 were $1: 20$ in the first and second blood samples. Four months later, when the girl had her second attack of aseptic meningitis, Coxsackie B2 was isolated from her stools. Serologically there was then a fourfold rise in homotypic antibody titre from $1: 2$ to $1: 8$. Thus it seems that these attacks were of a different aetiology.

Serological tests for mumps, herpes simplex, polio 1-3, adenoviruses, ornithosis, louping ill, leptospires, and syphilis were negative. In Case 1 in 1961 and 1962 and in Case 2 in 1962 the spinal fluid was examined for cryptococci with negative results.

\section{Discussion}

The clinical features and the results of the virological studies argue in favour of the assumption that in every individual case the syndrome was caused by an acute neurotropic infection and was not a manifestation of some other disease of the C.N.S., such as a neoplasm, aneurysm, multiple sclerosis, cerebral abscess, or cerebral lues. Although virological studies carried out before 1959 were inadequate, an enterovirus could be isolated from stools in five attacks out of 11. Most of the isolations were made after 1959: Coxsackie B5 three times in 1961-2, Coxsackie B2 once in 1962, and the only untyped virus (E.C.H.O. 9?) was from the year 1957. In all attacks antibody responses suggested that the disease might have been caused by the virus isolated. In addition to isolations, serological evidence of infection with E.C.H.O. 7 was shown in one attack, although no virus could be isolated from the stools. Thus a virus possibly responsible for the aseptic meningitis in these cases after 1959 was discovered in five out of six attacks. The aetiological agents were viruses which were epidemic in Finland at the times in question. In two of our four patients we could establish that different viruses-E.C.H.O. 7 and Coxsackie B5 with an interval of 17 months (Case 1) and Coxsackie B5 and Coxsackie B2 with an interval of four months (Case 4) appeared to be responsible for the attacks of meningitis.

The unknown aetiology of the other attacks sustained by our patients is by no means evidence that they were not caused by viruses. It is well known that in one-third of the cases of aseptic meningitis even in material subjected to the most thorough examination-for example, Meyer et al. (1960)-the aetiology remains obscure. Even though our study is suggestive of a differing viral aetiology in successive attacks of aseptic meningitis, the possibility must also be considered that the same virus might repeatedly cause the disease as in recurrent herpes simplex infection. No significant rise in antibody response to herpes simplex was shown in any of our patients.

Many viral diseases result in a good specific immunity and a recurrence of the same disease is unusual. As aseptic meningitis may be caused by many different viruses and some other microorganisms, the syndrome may well have a different aetiology in each attack. However, multiple attacks of aseptic meningitis

\begin{tabular}{|c|c|c|c|c|c|c|c|c|c|c|c|c|}
\hline \multirow[b]{2}{*}{$\begin{array}{l}\text { Case } \\
\text { No. }\end{array}$} & \multicolumn{3}{|c|}{ First Attack } & \multicolumn{3}{|c|}{ Second Attack } & \multicolumn{3}{|c|}{ Third Attack } & \multicolumn{3}{|c|}{ Fourth Attack } \\
\hline & $\begin{array}{c}\text { Month and } \\
\text { Year of } \\
\text { Attack }\end{array}$ & $\begin{array}{c}\text { Virus } \\
\text { Isolation }\end{array}$ & $\begin{array}{l}\text { Neutralizing } \\
\text { Antibodies }\end{array}$ & $\begin{array}{c}\text { Month and } \\
\text { Year of } \\
\text { Attack }\end{array}$ & $\begin{array}{l}\text { Virus } \\
\text { Isolation }\end{array}$ & $\begin{array}{l}\text { Neutralizing } \\
\text { Antibodies }\end{array}$ & $\begin{array}{c}\text { Month and } \\
\text { Year of } \\
\text { Attack }\end{array}$ & $\begin{array}{c}\text { Virus } \\
\text { Isolation }\end{array}$ & $\begin{array}{l}\text { Neutralizing } \\
\text { Antibodies }\end{array}$ & $\begin{array}{c}\text { Month and } \\
\text { Year of } \\
\text { Attack } \\
\end{array}$ & $\begin{array}{c}\text { Virus } \\
\text { Isolation }\end{array}$ & $\begin{array}{l}\text { Neutralizing } \\
\text { Antibodies }\end{array}$ \\
\hline 1 & III $/ 52$ & Not done & N.S. & $\mathrm{x} / 58$ & Neg. & $\begin{array}{l}\text { No antibody } \\
\text { responses } \\
\text { detected }\end{array}$ & $\mathrm{V} / 61$ & Neg. & $\begin{array}{c}\text { E.C.H.O. } 7 \\
\text { II } 1:<44^{*} \\
\text { III } 1: 464 \\
\text { III } 1: 64\end{array}$ & $x / 62$ & Coxs. B5 & $\begin{array}{c}\text { Coxs. } B 5 \\
\text { I } 1:<4 \\
\text { II } 1: 64\end{array}$ \\
\hline 2 & III $/ 52$ & Not done & N.S. & $\mathrm{V} / 57$ & $\begin{array}{c}\text { C.P.E. }+ \\
\text { untyped } \\
(\text { E.C.H.O. } \\
9 \text { ? })\end{array}$ & $\begin{array}{l}\text { Convalescent } \\
\text { serum not } \\
\text { available }\end{array}$ & VIII/61 & Neg. & $\begin{array}{l}\text { No antibody } \\
\text { responses } \\
\text { detected }\end{array}$ & & & \\
\hline 4 & IX/61 & Coxs. B5 & $\begin{aligned} \text { Coxs. } & B 5 \\
\text { I } 1 & : 20 \\
\text { II } 1 & : 20\end{aligned}$ & $1 / 62$ & Coxs. B2 & $\begin{array}{c}\text { Coxs. B2 } \\
\text { II }: 2 \\
\text { II } 1: 8\end{array}$ & & & & & & \\
\hline
\end{tabular}


seem to be uncommon both in our own experience and according to the literature, where we have been unable to find any reports of similar cases. A total of 450 patients with the diagnosis of aseptic meningitis were treated during 1952-62 at Aurora Hospital (formerly the Hospital for Infectious Diseases in Helsinki), which admits the majority of children and adults taken ill with meningitis in Helsinki. Three of the 450 patients suffered from aseptic meningitis on two or more occasions during this period. This incidence, $0.7 \%$, can naturally be regarded as a minimum.

The occurrence of two attacks of aseptic meningitis is not in itself extraordinary. But an explanation is required when, as with two of our patients, there are still further attacks. When this happens it is necessary to try very carefully to exclude all other possible diseases of the C.N.S. as well as bacterial parameningeal infections. Nothing indicative of such diseases was found in our cases. It is, of course, regrettable that no carotidangiography or pneumo-encephalography was performed on these patients. On the other hand, these procedures are not very readily undertaken when the disease is cured rapidly without sequelae. The histories indicated that these patients had no predisposition to infectious diseases. Electrophoresis showed normal amounts of gamma-globulins. Anyway, the patients with repeated attacks of aseptic meningitis in their history must have a special tendency toward such infections. However, we were unable to find any local or general reason for lowered resistance in these patients. A local congenital or acquired anatomical anomaly must nevertheless be seriously considered. Nor can the possibility be excluded that these individuals have some defect in their cell-bound defence mechanisms. A third possible explanation may be the development of hypersensitive (allergic) reactivity of the meningeal tissue to certain viral antigens.

\section{Summary}

Multiple attacks of typical aseptic meningitis were established in four patients: in two adults, one three times and the other four times, and in two children, twice in each. The follow-up periods were 18 months to 11 years. The intervals between the individual attacks were from four months to eight years.

An enterovirus isolation from the stools succeeded in 5 attacks out of 11: Coxsackie B5 three times, Coxsackie B2 once, and an untyped virus (E.C.H.O. 9?) once. Antibody responses indicated that the attacks may have been caused by the viruses isolated. In addition to the virus isolations, serological evidence of infection with E.C.H.O. 7 was obtained in one attack. In two patients different viruses appeared to be responsible for the successive attacks of meningitis.

No general or local cause was found for the predisposition towards aseptic meningitis in these patients.

This investigation indicates that different viruses may be responsible for successive attacks of aseptic meningitis in the same individual.

We express our gratitude to the following microbiologists who co-operated with us in clarifying the aetiology of meningitis: Dr. O. Wager and Dr. E. Jansson, Microbiological Laboratory, Aurora Hospital ; Professor N. Oker-Blom, Professor P. Halonen, and Dr. A. Salminen, Department of Virology, University of Helsinki ; and Dr. Kari Penttinen, M.D., State Serum Institute. We also thank Professor N. Hallman, who placed at our disposal the hospital records of patients with meningitis treated at the Children's Hospital, University of Helsinki.

\section{REFERENCES} Meyer, H. M., Johnson, R. T., Crawford, I. P., Dascomb, H. E., and
Rogers, N. G. (1960). Amer. F. Med., 29, 334 . Wallgren, A. (1925). Acta. paediat. (Uppsala), 4, 158.

\section{Preliminary Communications}

\section{Observations on Progeny of Thalidomide- treated Male Rabbits}

\section{Brit. med. F., 1964, 1, 1090-1091}

In earlier work (Lutwak-Mann and Hay, 1962) we found that maternally administered thalidomide produces peculiar changes in the configuration of the embryonic disk of pre-implantation rabbit blastocysts. The study of the action of maternally transmitted thalidomide upon pregnancy in the rabbit was continued and extended by Hay (1964). It was next decided to examine also the effect of thalidomide administered to males upon the breeding performance, to see if paternal treatment with this drug could affect progeny.

Experimental Animals.-Male rabbits (6) were chosen for consistently high fertility during 14 months of repeated matings ; they were again mated twice before the start of the thalidomide treatment to make certain that they were capable of producing good-quality litters. The females (40) were picked for their excellent fertility as well as maternity records, each having raised without loss at least two litters of not fewer than $\delta$ and up to 11 young prior to the experimental matings with the thalidomide-treated bucks. It may be added that the conception rate in our colony is $97 \%$, and the average number of young at birth is nine.
Thalidomide was fed to males in eapsules, in divided doses ; the courses of treatment are stated in the Table. Body weights were recorded throughout the experimental period, but no significant changes were noted and the animals appeared to be in good health during the whole time. The bucks were mated to does after thalidomide-free intervals extending from 2 to 10 weeks. The progress of pregnancy was checked by palpation from day 8 post coitum. The offspring were counted at birth, weighed, and inspected for abnormalities. They were maintained for up to 14 days, when the survivors were again counted and weighed as well as sexed, before the termination of the experiment. No appreciable alteration of the sex ratio was observed.

\section{RESULTS}

Experiment 1 (see Table) records observations made with two males, A and B. It can be seen that total loss of litters fathered by these two thalidomide-fed rabbits occurred in each case-for male $A$ at 4 weeks and for male B at 10 weeks from the end of their treatment with thalidomide. These two males were retained without further treatment for another four and a half months; during that period each was twice mated, with the following results : for $A$, one failure to induce conception (confirmed at necropsy of the doe on day 10 p.c.) and one viable litter ; for $\mathrm{B}$, one pseudopregnancy (confirmed at necropsy of the doe on day 10 p.c.) and one viable litter. These findings are not recorded in the Table, but will be taken into account in assessing the results. 